\title{
A Use Case of the Application of Advanced Gaming and Immersion Technologies for Professional Training: The GAMEPHARM Training Environment for Physiotherapists
}

\author{
Dimitra Pappa and Homer Papadopoulos \\ National Center for Scientific Research "Demokritos", Attiki, Greece \\ dimitra@dat.demokritos.gr \\ homerpap@dat.demokritos.gr \\ DOI: 10.34190/JEL.17.2.08
}

\begin{abstract}
Immersive technologies are gaining momentum in professional training. Advanced AR/VR and gaming technologies allow for authentic learning experiences that are close to real-life conditions, problems, and applications, something that can revolutionise fields like medical training, which traditionally relied on textbook-based theoretical education and clinical placements. The present paper discusses the application of advanced gaming and immersion technologies for the continuous training of physiotherapists. Presently, this professional group remains largely underserved by online training services. The paper argues that the inherent complexity of physical therapy training could be served effectively by immersive learning innovations and professionals could benefit greatly. The paper applies the Design Science Research Methodology (DSRM) to design a suitable training solution for the promotion of authentic, comprehensive learning. Our analysis targets and consolidates the findings from three distinct pillars: (a) the requirements of the application area in question; (b) the current state-of-the-art and emerging directions in game-based professional education and training; and (c) existing applications of game-based learning in the field of healthcare. Subsequently, the paper consolidates the findings to produce the system requirements and presents the design of a prototype training environment for physiotherapists that builds on advanced gaming technologies. Within the proposed system design, augmented reality modules are embedded alongside the game simulation and virtual world environment to provide participants with an authentic simulated game scenario in which to immerse themselves.
\end{abstract}

\section{Introduction}

Digital technologies are constantly changing the nature of education and learning. While the potential of gaming and gamification as enablers of learning is increasingly acknowledged, and despite the enormous progress in technologies, online professional learning still seems attached to conservative elearning approaches. To a large extent, these methods merely replicate the traditional classroom environment. As a result, professional learning fails to effectively leverage new technologies, like emerging gaming and immersion technologies. Consequently, in some professional areas, the effectiveness and impact of online professional learning are limited. Its services appear outdated and quite unattractive to modern users, who are native to novel technologies and applications, like elaborate simulations and leisure games since their young age.

The present paper discusses the new opportunities created by advanced gaming and immersion technologies for professional learning and investigates their assimilation for the continuous training of physiotherapists. We acknowledge that emerging gaming and immersion technologies are not directly transferable to adults in the workplace without additional investigation and adaptation to the needs of each sector. A thorough investigation of all parameters is needed. In this light, the present paper presents the design process of the GAMEPHARM prototype training system for physiotherapists that builds on advanced gaming technologies. It aims to explore innovative gaming technologies to create an immersive environment for online professional skills development that breaks away from the traditional norms. Physical therapy is a type of treatment that encompasses a wide variety of aspects (kinesiology, physiology, pathophysiology to mention but a few) and takes place in a variety of healthcare settings. Given the inherent complexity of physical therapy, physiotherapists are largely underserved by current training services. Physiotherapist training is a challenging application area that could benefit greatly from the introduction of gaming innovations and immersion technologies (Mori et al., 2015; Roberts \& Cooper, 2017).

Virtual world environments and augmented reality technologies hold the promise of integrating the experiential and interpretive dynamics of the learning experience. Virtual reality technologies and approaches 
that combine a real environment with virtual objects and information provide better reality and immersiveness to the subjects. Furthermore, they cater to a safer environment for experimentation and a motivating context for skill practice. Virtual reality approaches offer useful learning contents, which immediately can be put into practice, by maximising the interaction between real-time and sensory information (Azuma et al., 2001).

In the light of the above, the principal challenge addressed by the present work is how to implement innovative gamification techniques and state of the art gaming technologies, to create an immersive environment for online professional skills development that breaks away from traditional norms, to align with the complex needs of the targeted sector. More specifically, our main question is how to integrate augmented and virtual reality immersive environments, alongside other gaming modules, to improve the learning experience and achieve greater transference to physiotherapist practice. This question highlights a current gap, which triggered the motivation to design a novel immersive training environment. The GAMEPHARM solution builds on a foundation of open source virtual world technologies, enriched with augmented reality and gaming modules. In this environment, learning objectives are seamlessly interwoven with game objectives to offer a solution that enhances learner experience.

Considering that the skills development process is a highly personalised activity that is different for every individual, GAMEPHARM explores different approaches to authenticity, realism and gaming. The resulting solution represents an enhanced gaming environment that features an array of advanced gaming modules and tools to support adaptive, personalised storylines for professional skills development.

\subsection{Research Methodology}

To derive the appropriate training service mix, we followed a problem-centred approach that builds on the principles of the Design Science Research Methodology (DSRM) for Information Systems development (Peffers et al. 2007; Hevner et al. 2004). In the design-science paradigm, building and application of the designed artefact create knowledge and understanding of a problem domain and its solution. The present paper focuses on the early stages of the DSRM methodology, starting from the identification of opportunities for innovation to the design of the GAMEPHARM system (Figure 1).

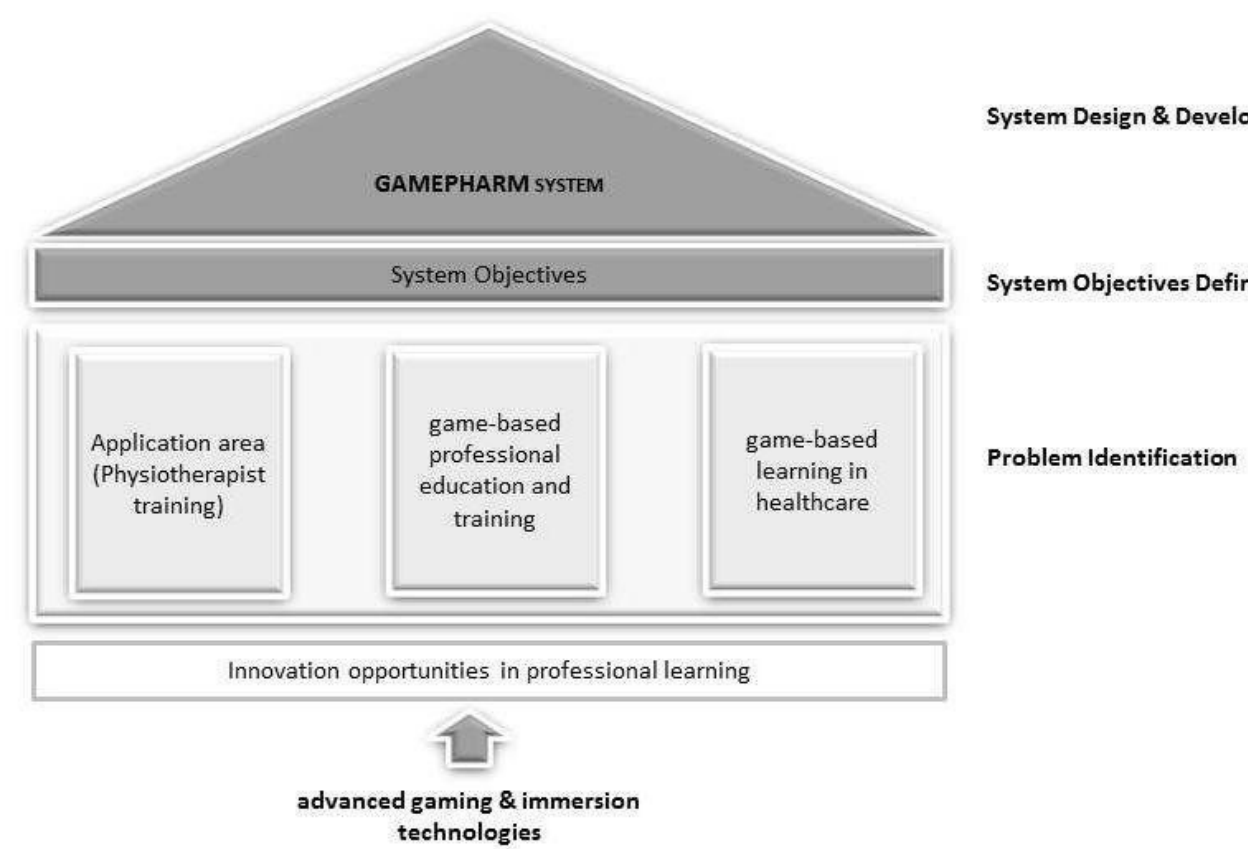

Figure 1: DSRM process for the GAMEPHARM system: from identification of innovation opportunities to system design

The paper reports on the current progress and discusses the early findings of an on-going research effort (Pappa \& Papadopoulos, 2018). The objective is to provide a comprehensive and extended account of the theoretical background, the design and the application of advanced training technologies for professional training in healthcare. Section 2 reports on the problem identification. Training strategies must build upon the 
specific needs and requirements of the application domain, both regarding processes and users targeted. For this reason, there is a need for the development of a new approach, using existing tools and customising others where necessary. To derive the objectives of the GAMEPHARM system, we investigated three distinct pillars: (a) the requirements of the application area in question; (b) the current state-of-the-art and emerging directions in game-based professional education and training; and (c) existing applications of game-based learning in the field of healthcare. The paper first discusses the characteristics of physiotherapist training.

Following, we investigate the opportunities offered by and the ways in which gaming and new immersion/augmentation technologies can enhance professional education and the training of medical professionals in particular. We then describe the development of the GAMEPHARM concept for the continuous training of health professionals in the field of physiotherapy. In this process, the paper discusses the important role that gaming and augmentation technologies increasingly play in healthcare professional education and reviews state-of-the-art applications and best practices in the field. Subsequently, the paper consolidates findings to produce the system requirements and presents the design of a prototype training environment for physiotherapists that builds on advanced gaming technologies. Section 3 is dedicated to the definition of the objectives of the design process, discussing the characteristics of the desired solution. Section 4 describes the design and development, outlining the core elements of the GAMEPHARM concept and Section 5 concludes the paper.

\section{Problem Identification}

\subsection{The application area: Physiotherapist training}

Physiotherapy refers to the identification, recovery, improvement, and maintenance of a person's movement abilities. Physiotherapists should be able to analyse and assess the functional and physical state of a person, treat by movement, physical factors, compensate disability, guarantee health care and prevention, and stimulate and educate healthy living. Physiotherapists are also facing the need to manage psychological issues that impact rehabilitation. Professional learning and development of physiotherapists are pursued through a range of learning programmes, increasingly involving advanced technologies (Stiller et al. 2004; Mori et al., 2015; Jones et al., 2017; Roberts \& Cooper, 2017; Phillips et al., 2017). The training involves both periods of theory and clinical experience gained by meeting and working with patients. The theoretical part of the training program covers anatomy, physiology, physics and pathology. It also features courses to develop communication skills, knowledge of psychology and to gain experience of practical treatment. Once qualified, physiotherapists usually begin in a rotational role, working in different departments for three to four months, and gaining experience in different specialities, e.g. outpatients, orthopaedics, etc. Newly qualified physiotherapists usually require clinical supervision on the job and mentorship support. They are encouraged to further develop their knowledge and skills by attending briefing sessions, short courses and reflective practice programmes. Physiotherapist training is a continuous process aimed at keeping professionals constantly up to date with new scientific insights, methods, technologies and tools in the profession. In some countries continuing professional development is mandatory to maintain the professional license. For example in the U.K., this is a requirement, to stay registered with the Health \& Care Professions Council (HCPC). For this purpose, a range of dedicated post-qualifying courses exist (regulatory training). Qualified physiotherapists may also opt to study for further specialist postgraduate qualifications, which can enhance career prospects.

Physiotherapist praxis requires multidimensional professional capabilities. Advanced gaming technologies allow for training that builds on experiential learning principles, pursuing the creation of holistic knowledge through the transformation of experience. This type of training can allow physiotherapists to gain a greater understanding of possible therapeutic interventions, and develop their clinical reasoning and decision making in the selection and justification of their chosen therapeutic approach. The GAMEPHARM prototype aims to empower physiotherapy professionals, by engaging them in "real-life", "real-time" personal learning experiences, powered by state-of-the-art gaming technologies. The objective is to transfer implementable knowledge in their day-to-day activities. On an ideation level, this implies a need for in-depth insight into the multidimensional professional skills needed. The design approach should thus first explore different professional situations, to gain a better knowledge of what a physiotherapist need to do, when, and why.

On a technology level, this creates the need for a multifaceted, modular approach. It implies the application of motor training solutions for physical training, i.e. the acquisition and retention of motor skills (muscle memory), with human anatomy simulation and others in the framework of virtual and augmented 
environments. Augmented reality technologies should provide among others a hands-on exploration of phenomena relating to human anatomy and secondary support-graphic panels, animations, etc. - to assist the physiotherapists in reflecting on the experience to further develop their clinical reasoning and decision making.

These technologies extend in scope the physiotherapist curriculum. Based on our preliminary analysis and past research experience, elderly fall prevention is an important subject in physiotherapist education that is suitable for experimentation with gaming and immersion technologies. Review of many published studies revealed that exercise-based programs for individuals at home or in group settings are effective in preventing falls (Lord et al., 1995; Rubenstein et al., 2000; Madureira et al., 2007; Gillespie et al., 2009; Clemson et al., 2012). The physical therapist is expected to design an exercise and training program to improve the balance and strength of individuals at risk of fall. One such intervention programs are the Otago Exercise Programme (OEP) (Campbell \& Robertson, 2010), which is a supervised home training programme, aimed at improving strength and balance and at reducing the fear of falling in older adults. Scientific evidence ascertains OEP's benefits for managing physiological falls risk by improving both functional mobility and cognitive performance (Liu-Ambrose et al., 2010).

The present work builds on the experience and lessons learned from the Prevention of Falls Network for Dissemination (ProFouND) project (ProFouND 2016a; 2016b). ProFound was an EC funded initiative that pursued the delivery of tutor training to health and leisure professionals across Europe, to create a cadre of accredited, qualified exercise trainers across Europe capable to implement exercise regimens that have been proven to reduce falls amongst older people, in order to deliver training in their local regions and extend exercise programmes. The project results led to coordinated approaches for the widespread implementation of OEP and the development of new tools to enhance that implementation. The ProFouND training model featured (a) the provision of e-learning services, via a dedicated online training portal supporting the dissemination of evidence-based good practice, and (b) the organisation of a series of face-to-face cascade training sessions across Europe. This endeavour, despite the promising outlook of the training method and the success of the regional training, was met with several challenges, mainly linked to the face-to-face activities (cost of face-to-face training, organisational burden and others) (ProFouND, 2016b), which call for further improvements in the methodology. The development of solutions for OEP training using advanced gaming and immersion technologies is expected to reduce, and eventually eliminate, the need for face-to-face training. The GAMEPHARM system aims to provide a viable solution in this direction.

\subsection{Game-based professional education and training}

Professional education is about building the knowledge, skills and competencies needed to support professional practice. Working in a certain profession, involves being able to act meaningfully and purposefully in real-life conditions, and to respond suitably in times of need. Professionals need to master the skills that are necessary for them to perform optimally under various professional situations, rather than possess a mere abstract, higher level understanding of the domain. The acquisition of problem-solving skills through hands-on experience is of paramount importance in most professions. Brown et al. (1989) stress that "knowledge is situated", being closely related to and not abstract table from the "activity, context, and culture in which it is developed and used".

For this reason, they recommend that learning should be embedded in an authentic situation. Reiners et al. (2015) describe authentic education as "a pedagogical model based on learning occurring within environments where practices and actions replicate those found in true-to-life situations, forcing learners to engage with similarly authentic materials and responses before receiving valuable feedback". Authenticity is a critical element of professional education and training, as a means to support both a person's entry into vocational practice and their continuing professional development (Eraut, 2002). Reiners et al. (2015) summarise the dimensions of an authentic learning strategy as follows:

- $\quad$ Providing an authentic context within which to situate the learning;

- Creating an authentic task that requires considerable time and effort in its completion;

- Providing access to expert performance and the modelling of processes to enable students to observe and critique;

- $\quad$ Providing a range of resources to enable students to access multiple perspectives; 
- Providing opportunities for students to collaborate with their peers in the creation of genuine and useful products;

- Providing opportunities to reflect, and articulate (spoken and written) their growing understanding;

- Providing scaffolding and support;

- Providing an authentic assessment to evaluate students' products.

Technology can play a critical role in this direction, facilitating the development of training solutions that approximate real-life conditions in a virtual space. It can provide a degree of authenticity that allows almost complete immersion of learners in given scenarios and "increased practice realism". Practice realism enables learners to familiarise themselves with professional activities, and problems within the context that produced them, and to "execute tasks and decision-making under more closely representative conditions" (Hsu et al., 2013). Technology-enhanced learning can incorporate thinking and problem-solving, as if learners were performing in a real-world environment, and target both the functional skills related to a particular profession and the associated "soft skills" (communication, collaboration and others).

In recent decades technology-enabled gaming environments have been used for a variety of educational tasks (Abt, 1970; Loftus \& Loftus, 1983; Egenfeldt-Nielsen, 2007; Susi et al., 2007), including the provision of vocational education in several sectors, e.g. military, medical, business, manufacturing, public sector etc. (De Freitas, 2006; Gavish et al., 2015; Matsas \& Vosniakos, 2017). Modern Game-Based Education/Learning (GBL) employs digital games to create "immersive digitally mediated learning environments" (Squire, 2011) that balance gameplay with pre-defined learning objectives (Protopsaltis et al., 2010). Applied solutions include games, serious games, virtual worlds and simulations (Ulicsak, 2010). Connolly et al. (2012) note that serious games can enhance the effectiveness of learning, improve knowledge acquisition and content understanding and also allow for affective and motivational outcomes. The intrinsic benefits of GBL solutions include personalised learning, active participation and interaction, and critical thinking, awareness of emotions, (collaborative) knowledge construction, creative problem solving and innovation. Their impacts span several dimensions: perceptual, cognitive, behavioural, affective and motivational (Connolly et al., 2012). As a result, GBL has rapidly gained momentum in all fields of education, including professional training. Compare to traditional training modalities that have significant limitations, featuring passive training based on theoretical instruction and memorisation, GBL allows for immersion and authentic learning experiences.

Although these experiences are close to real-world issues, problems, and applications, without the practical constraints of real-world settings to limit them, these also incorporate the essential ingredients of training.

Such learning experiences facilitate a deeper understanding and the assimilation of theory. Furthermore, they allow trainees to evaluate their skills in a variety of complex, real-life eventualities, which will ultimately allow them to perform consistently and effectively in their professional life, even in new and unexpected situations.

While early games provided limited capabilities, immersive technologies such as Virtual Reality (VR) and Augmented Reality (AR) are creating a new potential and a new paradigm for GBL (Psotka, 1995; Azuma et al., 2001; Slater et al., 2010; Bacca et al., 2014; Freina \& Ott, 2015; Allen et al. 2017). Burdea \& Coiffet (1994) define VR as "a high-end user interface that involves real-time simulation and interaction through multiple sensorial channels. The user is found completely immersed inside a synthetic Virtual Environment (VE) that can employ diverse sensorial modalities: visual, auditory, tactile, smell, end/or taste. Although AR systems lack presence (defined by Witmer and Singer (1998) as the subjective experience of being in one place or environment, even when one is physically situated in another), they can provide "local virtuality" (Van Krevelen \& Poelman, 2010) and lead to powerful context immersion (Kim, 2013).

In AR, real-world objects are "combined" or "supplemented" with virtual objects or superimposed information (Azuma, 1997; Bacca et al., 2014). Head-mounted displays (HMD) that propose relevant views of the visual world as the person moves their head, and sensors and tracking mechanisms (magnetic, mechanical, infrared, gyroscopic, etc.) that register the person's motions, gestures, and reactions and use these as input for modelling the display, allow for increasingly rich user experiences (Psotka, 1995). Beyond the emergence of serious games played through natural interfaces (Foletto et al., 2017; Bortone et al., 2017, Milani et al., 2017), this can lead to new learning services and applications about the traditional sense of space and place and the interaction with other humans. Psotka (1995) stressed the value of VR for "exploration" and training "practical 
skills, technical skills, operations, maintenance". Burdea (1993) defined the three key characteristics of VR as being: "immersion", "interactivity" and "imagination". Santos et al. (2014) identified the three main affordances of AR that make it suitable for education: "real world annotation", "contextual visualisation" and "vision-haptic visualisation".

The integration of GBL with artificial intelligence techniques can (a) provide more advantages, namely intelligent tutoring systems and intelligent narrative technologies (Lester et al., 2013), and (b) allow for adaptive educational systems, offering GBL experiences that are personalised to individual students (Lester et al., 2013; Colchester et al., 2017).

\subsection{GBL applications in healthcare}

The application of GBL in patient and health professional education is increasing (Issenberg et al., 1999; Arnab, 2012; Wattanasoontorn et al., 2013; de Ribaupierre et al., 2014; Drummond et al., 2017), including continuing medical education (Ricciardi \& Paolis, 2014). Sawyer \& Smith's (2008) taxonomy of serious games notes the application of SGs in healthcare for training healthcare professionals and patient education. A later taxonomy proposed by McCallum (2012) identifies five critical areas of application in the health domain (preventative, therapeutic, assessment, educational and informative) that span several stakeholder dimensions (personal, professional practice, research, and public health). All point to the widespread use of digital games explicitly designed for healthcare. Important application areas include preventative care, rehabilitation and behaviour modification for patients and education for medical professionals. For example, Graafland et al. (2012) studied several medical education serious games linked to the surgical practice to conclude that blended and interactive learning using serious games can be effectively applied to train both technical and non-technical skills relevant to the surgical field. In Table 1 we provide the latest research studies and application examples:

Table 1: digital games for healthcare

\begin{tabular}{|c|c|}
\hline Health purpose & Indicative Applications \\
\hline $\begin{array}{l}\text { PREVENTION } \\
\text { preventative care \& health } \\
\text { promotion }\end{array}$ & $\begin{array}{l}\text { - Active, healthy ageing } \\
\text { - Diagnosis/detection (e.g. cognitive screening) } \\
\text { - Cognitive improvement (e.g. dementia games) }\end{array}$ \\
\hline $\begin{array}{l}\text { THERAPY } \\
\text { therapeutic intervention } \\
\text { (rehabilitation \& disease } \\
\text { management) }\end{array}$ & $\begin{array}{l}\text { - Study of rehabilitation featuring games for physical, social and mental } \\
\text { activity } \\
\text { - Cognitive training (e.g. stroke or cancer patients) } \\
\text { - Motor rehabilitation, e.g. Upper limb rehabilitation, traumatic bone/soft } \\
\text { etc. tissue injuries }\end{array}$ \\
\hline $\begin{array}{l}\text { MENTAL HEALTH } \\
\text { mental health \& behaviour } \\
\text { modification }\end{array}$ & $\begin{array}{l}\text {-mental health } \\
\text {-health behaviour change }\end{array}$ \\
\hline $\begin{array}{l}\text { EDUCATION } \\
\text { medical education }\end{array}$ & $\begin{array}{l}\text {-surgical skills training } \\
\text {-anatomy: 3D models of organs } \\
\text {-medical cultural competence education } \\
\text { - examination skill development (case of eye fundus) } \\
\text {-patient communication } \\
\text {-computer supported reflection }\end{array}$ \\
\hline
\end{tabular}

Amidst constant changes in medical practice, advanced GBL solutions for medical education provide a method for practising professionals to get into contact with new knowledge and ideas through hands-on experience.

Furthermore, they allow health professionals to become self-directed lifelong learners (Issenberg et al., 1999).

Beyond knowledge of specific medical and care topics and/or technical and operational competencies for the delivery of a high standard of therapy and care, the training of medical professionals also involves the development of soft skills and interpersonal or social competencies, such as coping with demanding situations or conducting conversations with patients and relatives and others. Serious games for health can support all of these learning objectives. 
To address these wide-ranging topics, several types of serious games applications have emerged. Ushaw \& Morgan (2017) identified five classes of benefit delivery mechanism which are applicable across all types of serious games for health (repetition, exploration, strategy, progressive goal attainment and social interaction).

For example, Piromchai (2014) recognised the value of VR systems for self-directed learning for Surgical Training, stressing the ability of virtual reality to provide repetitive practice under a controlled environment.

\section{Defining Objectives of the Solution}

In GAMEPHARM emphasis will be placed on authentic and experiential learning (i.e. learning through reflection on doing). Through gaming, individuals will have the opportunity to participate and experiment in real-life inspired scenarios. Kolb's experiential learning model states that "learning is the process whereby knowledge is created through the transformation of experience". The theory presents a cyclical model of learning, consisting of four stages: (a) concrete experience (or "DO"), (b) reflective observation (or "OBSERVE") (c) abstract conceptualisation (or "THINK") and (d) active experimentation (or "PLAN")

Building on a foundation of open source virtual world technologies, enriched with augmented reality and leisure gaming modules, GAMEPHARM will offer a solution that enhances the learner's experience, where learning objectives are seamlessly interwoven with game objectives. Immersive environments can provide a better understanding, improve context and situational awareness and enhance learning retention while helping contain the implementation costs (situated learning).

With the skills development process being a highly personalised activity that is different for every individual, the gaming environment will feature an adaptive storyline. At the centre of the action is the individual who interacts with the virtual environment by responding to challenges and opportunities, measuring and analysing the impact of those responses and, from the ensuing feedback is presented with fresh challenges and opportunities.

This functionality will build on the continuous and non-invasive assessment of learning progress (skills assessment) and motivation states (motivation assessment). Non-invasive, in-game experiments, coupled with explicit assessments, will allow the environment to ascertain whether users have reached their targeted learning objectives and their skills level at any point and time. Individual motivation to participate and engage is critical. Users become motivated to develop and continuously improve as long as each proposed action is attractive, accessible and affordable. The proposed solution will provide opportunities to enhance the experience and increase engagement, participation, and social interactions.

The technologies and modules embedded in the storyline will support personalisation of the learning process to engage and motivate individuals to develop continuously.

Technology integration will address physical training as well. GAMEPHARM will experiment with motor training, i.e. the acquisition and retention of motor skills (muscle memory) in the framework of a virtual environment as part of the first pilot (physical education trainers).

Overall, within GAMEPHARM, the proposed integration of new technology in physiotherapist training is not intended as a mere substitution exercise (Puentedura, 2006). Substitution refers to the use of new advanced technologies for service improvement, but without introducing functional change to the training that is on offer today. The present work aspires to achieve transformation (Puentedura, 2006). Aim of GAMEPHARM is to enable functionally improvements (augmentation) and redesign (modification) of current training tasks, and experimentation with training tasks that were not possible previously (redefinition).

We identified the following specific objectives during the development of the GAMEPHARM concept:

1. training objectives:

- Design an exercise and training program for physiotherapists to help them improve the balance and strength of their patients/subjects; 
- Train physiotherapists in specialised movement and balance therapies - lower body, walking activities and others;

2. functional objectives:

- Construct digital games to offer an enhanced, effective, non-threatening, fun, educational learning environment, allowing for increased student engagement and satisfaction;

- Increase engagement with the content or story, entertainment, education where possible and reasoning exercises (e.g. games that include puzzle solving and logic), to increase the retention and the transfer of knowledge;

- Emphasise experiential learning (i.e. learning through reflection on doing) and interpretive dynamics of the learning experience;

- Help physiotherapists to participate and experiment with real-life inspired scenarios in the game environment. Use immersive learning environments (combine a real environment with the virtual objects and information) to provide better understanding, improve context and situational awareness and enhance learning retention;

- Provide a safer environment for experimentation and a motivating context for skill practice;

- Allow for continuous reflection on stories and approaches, and the further refinement of the storyboards.

\section{GAMEPHARM concept design and development}

We design the GAMEPHARM concept on well-defined objectives, identified and elaborated following the DSRM approach. GAMEPHARM aims to experiment with innovative gaming technologies to create an immersive environment for online professional skills development that breaks away from the traditional norms. The design of the concept leverages and integrates existing technologies, with preference to open source technologies. Within GAMEPHARM, augmented reality modules will be embedded alongside the game simulation and virtual world environment to provide participants an authentic simulated game scenario, in which to immerse themselves. The real-life simulation via augmented reality or virtual world approaches, that can replicate elements of real-world situations to develop learning through action and interaction, is well documented (Gaba, 2004, Issenberg et al., 2005). However, the degree to which participants immerse themselves in the simulated environment is likely to be influenced by authenticity, realism and gaming techniques. Considering that the skills development process is a highly personalised activity that is different for every individual, the proposed solution explores different approaches to authenticity, realism and gaming.

GAMEPHARM represents an enhanced gaming environment that features an array of advanced gaming modules and tools to support adaptive, personalised storylines for professional skills development. At the centre of this virtual learning path is the individual, who interacts with the virtual environment by responding to dynamic challenges and opportunities. The system presents the trainee with explanatory feedback, based on the metrics and analytics of the responses, as well as with fresh challenges and opportunities. This functionality builds on the continuous and non-invasive assessment of learning progress (skills assessment) and motivation states (motivation assessment). By monitoring a user's progress through both non-invasive, ingame experiments and explicit assessments, the environment can ascertain whether users have reached their targeted learning objectives and monitor their skills level at any given point. Individual motivation to participate and engage is critical. Users become motivated to develop and continuously improve as long as each proposed action is attractive, accessible and affordable. The technologies and modules embedded in the storyline will support personalisation of the learning process to engage and motivate individuals to develop continuously. The proposed gaming approach will provide opportunities to enhance experience and increase engagement and participation.

\section{The GAMEPHARM architecture}

The architecture of GAMEPHARM (Figure 2) will consist of several subsystems that are integrated together to provide the user with a comprehensive, motivating experience:

\section{Open Simulator Virtual World Environment}

The virtual world is part of the platform and encapsulates all the interaction into a motivating coherent experience. On each progress, the user will receive positive feedback adjusted to their level, status and needs. This feedback will include gamification artefacts, e.g. badges and rewards (animations, new fun games, virtual 
coins and others). We will explore existing solutions like the OpenSimulator open source multi-platform, multiuser 3D application server (Opensimulator, 2018), to develop the virtual world environment.

2. AR-based virtual gaming environment for professional learning and skills acquisition

We will use open source AR gaming and interactive platforms for the creation of fully interactive virtual engaging AR training and learning experiences on top of standard guidebooks, workbooks, e-books, websites, equipment, posters and other traditional training materials. Physiotherapists will be able to benefit from AR games displaying human body sections in actual 3D action, using the hype realistic AR experience. Clinical tools and equipment will come to life, and the trainees will be able to "use" them while experimenting in the 3D virtual world within the realm of the game. The platform will be able to interact with virtual worlds and Learning Management Systems (LMS) forwarding information and data on all the user interactions inside the AR space.

\section{User management and Profiling Engine}

Users will get registered in the game application using an access and profiling module that manages and stores user profile information and system log and interaction data. A profiling engine will determine and suggest the right level and type of interaction that is suitable for each user, based on their profile, usage history (e.g., adjusting the level of difficulty according to previous success level), user selections and location in the virtual world (e.g., specific area/type of activity). The profiling engine will generate the appropriate action for each specific user, based on predefined scenarios, activities and contents.

\section{Advanced AR/VR technologies}

The system will expand into advanced technologies for the capturing of 3D-spaces and the development of applications that enable users to interact and alter such spaces. The former will involve the enhancement of existing technologies for the combination of 360-degree video capture with LIDAR/point-cloud data.

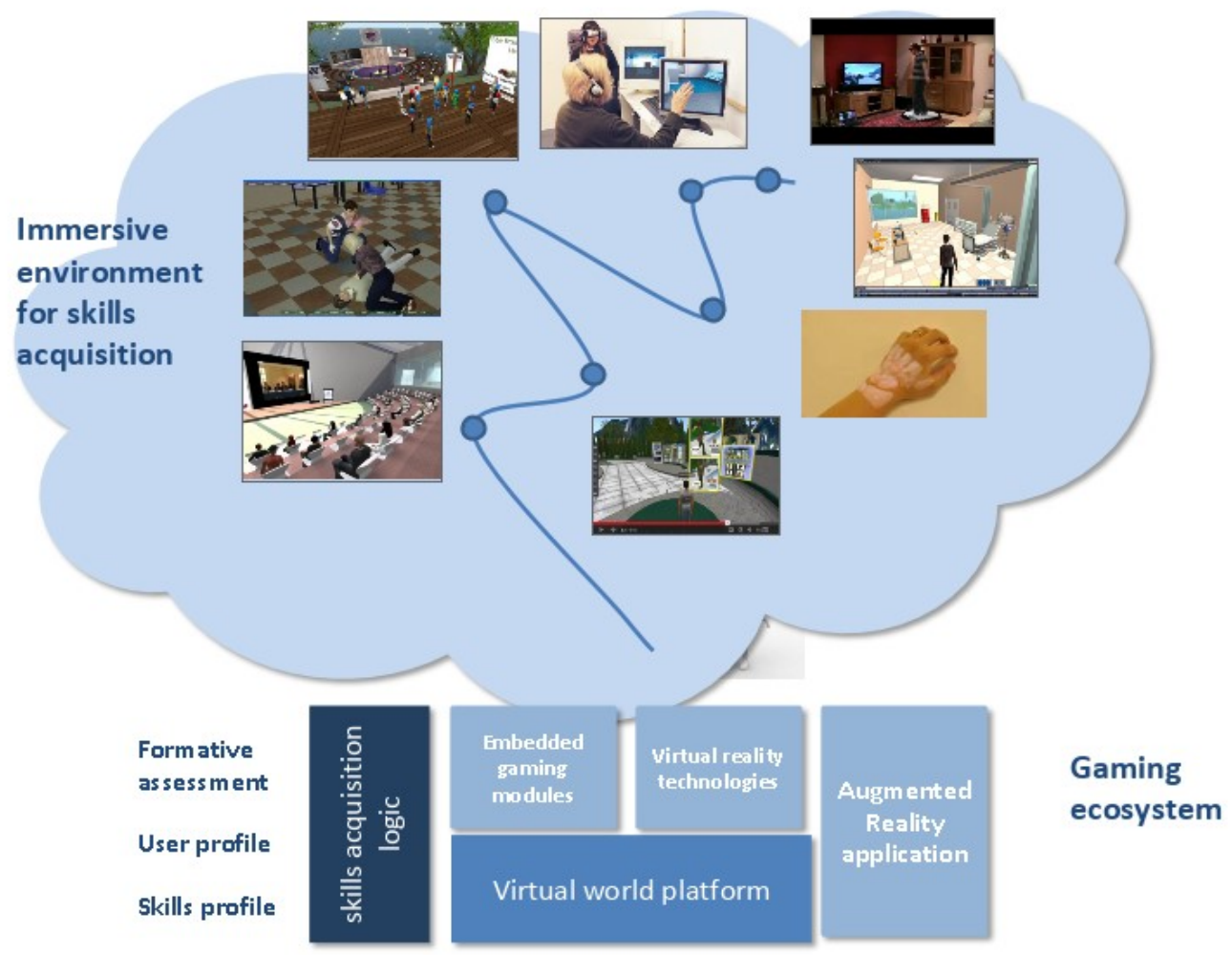

\section{Figure 2: GAMEPHARM system ARCHITECTURE}

Presently, apart from capture technologies (which have been both demonstrated and in limited use), the rest of the elements, which would complete a proper workflow involving web distribution, integration of haptic control and bespoke user interfaces, remain mostly independent of each other and appear to follow nonconnecting development paths. The result is that a unified environment, integrating a complete end-to-end 
workflow, from capture to immersive experience, does not exist today. This is particularly the case when dealing with complex workflows (e.g. services catering for the needs of physiotherapists).

\section{Discussion and Conclusions}

The present work proposes a new approach for physiotherapist training, founded on the exploitation of novel gaming and AR technologies, and the systematisation of the training process. Central to the GAMEPHARM training system is the "skills acquisition logic" module (Figure 2), which allows for training services orchestration and optimisation, in line with the actual training needs of the physiotherapist: their individual skills and preferences, their job requirements, and leaning progress. In analogy to the life cycle of business process oriented learning (Pappa, Faltin \& Zimmermann, 2009), starting point of the training process is the identification of the training needs of the learner. The training services life-cycle includes the following steps:

- Professional need analysis, which refers to the identification of skills required for a physiotherapist to properly and effectively carry out their functions

- The identification of skills gaps, which includes the calculation of overall skills gaps of the individual, by comparing physiotherapist's as-is and required skills profiles and the prioritisation of the skills gaps to be filled by means of training.

- The design of the training process, which involves the identification, and in case of lack thereof the creation, of appropriate learning materials and immersive experiences

- The execution of the training process, which consists in the physiotherapist being trained inside the GAMEPHARM immersive environment for skills acquisition, in order to fill their identified skills gaps.

- Performance monitoring, which involves an evaluation of the outcome of the training process both in terms of learning outcomes and professional performance of the trainee (formative assessment).

- Value analysis, during which the practical outcomes of the competency improvements are compared against the initial professional needs. Unless the results are deemed satisfactory, the training processes can be adapted and optimised further and a new training cycle may start comprising appropriate immersive training experiences.

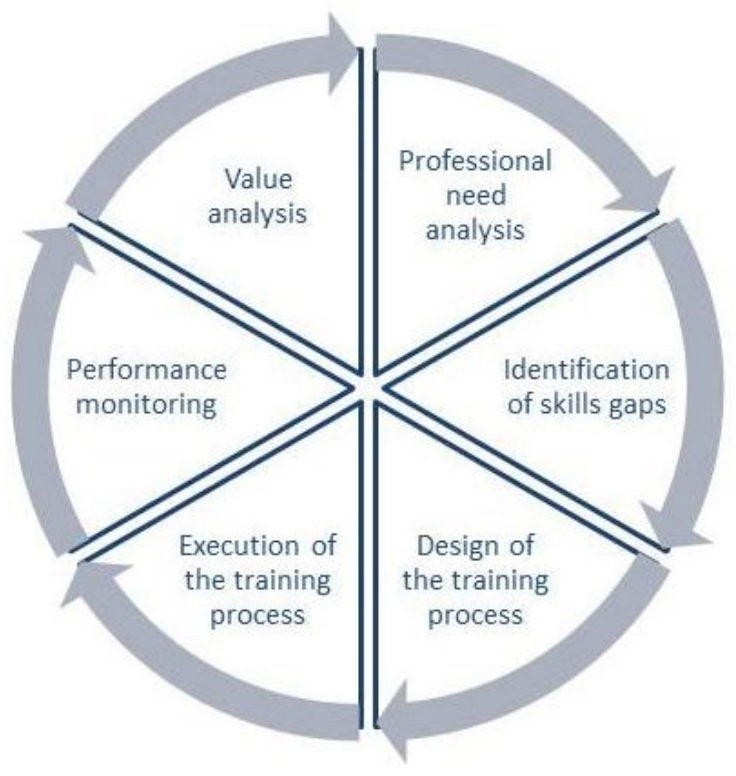

Figure 3: life-cycle of GAMEPHARM training services

This results in the creation of a flexible virtual learning path tailored to the needs of each individual physiotherapist who interacts with the virtual environment, to acquire and exercise "just-the-right" OEPrelevant skills they need.

Overall, GAMEPHARM aims to empower health professionals by engaging them in "real-life", "real-time" personal learning experiences, powered by state-of-the-art gaming technologies. The core of the GAMEPHARM approach is to explore situations to gain better knowledge of what to do, when, and why. The 
aim is to transfer implementable knowledge in the day-to-day activities of targeted professionals, namely to facilitate the uptake and effectiveness of evidence-based training programmes that build on the use of state-of the-art technologies: Behind the development of the GAMEPHARM concept stands the motivation to explore advanced immersive technologies, and effective and efficient game-based practices in the highly demanding domain of healthcare and wellness professional training, specifically focusing on the development of innovative methods for the provision of authentic, comprehensive training experiences to physiotherapists.

The GAMEPHARM system is expected to provide a viable solution for the widespread training of new and the continuous education of existing OEP practitioners. The PROFOUND experience has demonstrated that maintaining fidelity in and achieving the long-term sustainability of face-to-face cascade training can be problematic (PROFOUND, 2016b). The GAMEPHARM concept is designed to address these shortcomings striving for low cost, ease of implementation and ease of use, flexibility and effectiveness. It further strives for solutions that can be adopted by and be of value to professionals, but also for non-professional, social carers (family, friends and others).

For this purpose, GAMEPHARM combines different approaches to authenticity, realism, and gaming, to produce an enhanced gaming environment that supports adaptive, personalised storylines for professional skills development. The proposed gaming approach is designed to provide opportunities to enhance experience and increase engagement and participation. At the centre of this virtual learning path stands the physiotherapist who interacts with the virtual environment, to acquire and exercise OEP-relevant skills. The system provides the user with feedback by measuring and analysing the impact of their performance, as well as with fresh challenges and opportunities to enhance their learning. The learning approach builds on the continuous and non-invasive assessment of learning progress (skills assessment) and motivation states (motivation assessment). By monitoring a user's progress through in-game experiments in a non-invasive manner, as well as through explicit assessments, the environment will ascertain whether users have reached their targeted learning objectives and their skills level at any point. Individual motivation to participate and engage is critical. Learners become motivated to develop and continuously improve as long as each proposed action is attractive, accessible and affordable. The technologies and modules embedded in the storyline will support personalisation of the learning process to engage and motivate individuals to develop continuously.

Training adaptation will focus on usability/playability to engage trainees, rather than relying purely on visual stimulation. GAMEPHARM will encourage interaction with content and artefacts that is available within virtual and real-life environments, using virtual and augmented reality technologies respectively. Following the principles of game-based learning important elements of the training include the actual story/scenario (depth, detail and others), the setting or environment in which the story (game) takes place, logical flow (realism) and level design.

In Table 2, we summarise the key attributes of the GAMEPHARM training solution:

Table 2: GAMEPHARM training SOLUTION characteristics

\begin{tabular}{|c|c|c|}
\hline & Usability & $\begin{array}{ll} & \text { Provide help (when questioned/stuck) } \\
\text { - } & \text { Provide feedback (players respond to positive feedback after elegant } \\
& \text { solutions) } \\
\text { - } & \text { Avoid errors (inaccuracy in games are very frustrating) } \\
\text { - } & \text { Adapt the game to the player (e.g. change scenarios dynamically } \\
& \text { based on player feedback) }\end{array}$ \\
\hline & $\begin{array}{l}\text { Potential } \\
\text { stakeholder } \\
\text { roles }\end{array}$ & $\begin{array}{l}\text { - } \\
\text { - } \quad \text { Trainers (these could also be the carers that take care of the older } \\
\text { adults) } \\
\text { Patients (elderly with moving instabilities. This role will provide the } \\
\text { physiotherapists and trainers with the knowledge of how the older } \\
\text { adults perceive their context and the difficulties they experience) }\end{array}$ \\
\hline & Environments & $\begin{array}{ll}\text { - } & \text { Hospital wards (e.g. orthopaedic ward) } \\
\text { - } & \text { Elderly premise }\end{array}$ \\
\hline & Interactions & $\begin{array}{l}\text { - } \quad \text { Clinical cases (followed through their "lifetime," e.g. initial } \\
\text { assessment, treatment phase) } \\
\text { - } \quad \text { Ethical dilemmas }\end{array}$ \\
\hline$\bullet$ & Levels & - $\quad$ E.g. Level 1-Beginner \\
\hline
\end{tabular}


The GAMEPHARM design concept appears to be a promising aid when used additionally to training physiotherapists professionals. Expected outcomes of the GAMEPHARM game in the physiotherapist education include engagement with the content on a deeper, more exciting level, the introduction of key clinical concepts in a simulated but practical and safe environment, and others. This paper described the design process of the GAMEPHARM system. Analysis work built on the following three pillars: (a) the requirements of the application area (OEP physiotherapist training); (b) the current state-of-the-art and emerging directions in game-based professional education and training; and (c) existing applications of gamebased learning in the field of healthcare. Findings were consolidated to produce the system requirements and guide the design of the architecture of a prototype GAMEPHARM training environment.

While GAMEPHARM proposition builds upon very promising and challenging technology innovations, several barriers and constraints are still in place. The overall concept was formulated based on a holistic approach that can have significant impact on healthcare and wellness stakeholders, intermediaries and end users. We seek to proceed in the development of the training game within the framework of a funding project to achieve quality of training in this key health area and promote learning for the future. Researchers should validate the GAMEPHARM system artefact after the development phase. In this context, the whole GAMEPHARM system will be fully evaluated, improved and validated, using lab testing and pilot studies. For this purpose, we have examined several evaluation methods, such as the RETAIN model (Gunter et al., 2007), which proposes the following criteria: Relevance, Embedding, Transfer, Adaption, Immersion and Naturalisation. These trials will demonstrate the efficacy of the proposed system to provide better training in real-life use cases for physiotherapist and help draw sustainable pathways for the service's rollout. This work will also inform plans for the adaptation/customisation of GAMEPHARM for use by other user groups and in other application contexts.

The present paper explored the feasibility and relevance of this new physiotherapist training approach based on theoretical background knowledge, relevant best practices and technological state-of-the-art. Practical results regarding the effectiveness of the GAMEPHARM system and methods will be revealed during the rollout and real-life validation of the service.

The upshot of the presently reported findings concern (a) the researchers, who have to consider the proposed method as a promising approach for future research regarding real-life training experiences to medical personnel, and (b) the educational professionals, who have to consider the benefits of the above concept about the design of training processes to support lectures. Our preliminary findings confirm existing research studies that ICT advances should be part of the healthcare professional training process. Because our purpose was to suggest an innovative method and not to describe an existing running prototype, we should not draw far-reaching conclusions from the proposed concept and interpret this study in the light of this limitation.

\section{References}

Abt, C. (1970). Serious games. New York: Viking Press.

Arnab, S. (Ed.). (2012). Serious games for healthcare: applications and implications. IGI Global.

Azuma, R. (1997). A survey of augmented reality. Presence-teleoperators and Virtual Environments, 6(4), 355-385.

Azuma, R., Baillot, Y., Behringer, R., Feiner, S., Julier, S., \& Maclntyre, B. (2001). Recent advances in augmented reality. IEEE computer graphics and applications, 21(6), 34-47.

Bacca, J., Baldiris, S., Fabregat, R., \& Graf, S. (2014). Augmented reality trends in education: a systematic review of research and applications. Journal of Educational Technology \& Society, 17(4), 133.

Bortone, I., Leonardis, D., Solazzi, M., Procopio, C., Crecchi, A., Bonfiglio, L., \& Frisoli, A. (2017, July). Integration of serious games and wearable haptic interfaces for Neuro Rehabilitation of children with movement disorders: A feasibility study. In Rehabilitation Robotics (ICORR), 2017 International Conference on (pp. 1094-1099). IEEE.

Brown, J. S., Collins, A., \& Duguid, P. (1989). Situated cognition and the culture of learning. Educational researcher, 18(1), 32-42.

Burdea, C.G. \& Coiffet, P. (1994). Virtual reality technology. London: Wiley-Interscience.

Campbell, A. J., \& Robertson, M. C. (2010). Comprehensive approach to fall prevention on a national level: New Zealand. Clinics in geriatric medicine, 26(4), 719-731. 
Clemson, L., Singh, M. A. F., Bundy, A., Cumming, R. G., Manollaras, K., O'Loughlin, P., \& Black, D. (2012). Integration of balance and strength training into daily life activity to reduce rate of falls in older people (the LiFE study): randomised parallel trial. BMJ, 345, e4547.

Colchester, K., Hagras, H., Alghazzawi, D., \& Aldabbagh, G. (2017). A survey of artificial intelligence techniques employed for adaptive educational systems within E-learning platforms. Journal of Artificial Intelligence and Soft Computing Research, 7(1), 47-64.

Connolly, T. M., Boyle, E. A., MacArthur, E., Hainey, T., \& Boyle, J. M. (2012). A systematic literature review of empirical evidence on computer games and serious games. Computers \& Education, 59(2), 661-686.

De Freitas, S. (2006). Learning in immersive worlds: A review of game-based learning. Available online at: https://www.webarchive.org.uk/wayback/archive/20081225021139/http://www.jisc.ac.uk/media/docu

De Ribaupierre, S., Kapralos, B., Haji, F., Stroulia, E., Dubrowski, A., \& Eagleson, R. (2014). Healthcare training enhancement through virtual reality and serious games. In Virtual, Augmented Reality and Serious Games for Healthcare 1 (pp. 927). Springer, Berlin, Heidelberg.

Dillenbourg, P., Schneider, D., \& Synteta, P. (2002). Virtual learning environments. In 3rd Hellenic Conference" Information \& Communication Technologies in Education" (pp. 3-18). Kastaniotis Editions, Greece.

Drummond, D., Hadchouel, A., \& Tesnière, A. (2017). Serious games for health: three steps forwards. Advances in Simulation, 2(1), 3.

Eraut, M. (2002). Developing professional knowledge and competence. Routledge.

Foletto, A. A., Cordeiro, M. D. O., \& Cervi, A. P. (2017). Serious Games for Parkinson's Disease Fine Motor Skills Rehabilitation Using Natural Interfaces. Studies in health technology and informatics, 245, 74-78.

Freina, L., \& Ott, M. (2015). A literature review on immersive virtual reality in education: state of the art and perspectives. In The International Scientific Conference eLearning and Software for Education (Vol. 1, p. 133). " Carol I" National Defence University.

Gaba, D. M. (2004). The future vision of simulation in health care. Quality \& Safety in Health Care, 13, 2-10.

Gavish, N., Gutiérrez, T., Webel, S., Rodríguez, J., Peveri, M., Bockholt, U., \& Tecchia, F. (2015). Evaluating virtual reality and augmented reality training for industrial maintenance and assembly tasks. Interactive Learning Environments, 23(6), 778-798.

Gillespie, L.D., Robertson, M.C., Gillespie, W., Sherrington, C., Gates, S., Clemson, L., \& Lamb, S.E. (2009). Interventions for preventing falls in older people living in the community. The Cochrane database of systematic reviews, 2, CD007146.

Graafland, M., Schraagen, J. M., \& Schijven, M. P. (2012). Systematic review of serious games for medical education and surgical skills training. British journal of surgery, 99(10), 1322-1330.

Gunter, G.A., Kenny, R. F. \& Vick, E.H.(2007). Taking educational games seriously: using the RETAIN model to design endogenous fantasy into standalone educational games, Education Tech Research Dev (2008) 56:511-537

Hevner, A. R., March, S. T., Park, J., \& Ram, S. (2004). Design science in information systems research. MIS Quarterly, 28(1), 75-105.

Hsu, E.B., Li, Y., Bayram, J.D., Levinson, D.M., Yang, S.C., \& Monahan, C. (2013). State of Virtual Reality Based Disaster Preparedness and Response Training. PLoS Currents.

Issenberg, S. B., McGaghie, W. C., Hart, I. R., Mayer, J. W., Felner, J. M., Petrusa, E. R., ... \& Gordon, D. L. (1999). Simulation technology for health care professional skills training and assessment. Jama, 282(9), 861-866.

Issenberg, S. B., McGaghie, W. C., Petrusa, E. R., Gordon, D.G., \& Scalese, R. J. (2005). Features and uses of high-fidelity medical simulations that lead to effective learning: A BEME systematic review. Medical Teacher, 27(1), 10-28.

Jones, A., Mandrusiak, A., Judd, B., Gordon, C., \& Alison, J. (2017). Investigating a Physiotherapy Clinical Simulation Assessment Tool Using The Delphi Approach. Internet Journal of Allied Health Sciences and Practice, 15(3), 3.

$\mathrm{Kim}$, M. J. (2013). A framework for context immersion in mobile augmented reality. Automation in construction, 33, 79-85.

Lester, J. C., Ha, E. Y., Lee, S. Y., Mott, B. W., Rowe, J. P., \& Sabourin, J. L. (2013). Serious games get smart: Intelligent gamebased learning environments. Al Magazine, 34(4), 31-45.

Liu-Ambrose, T., Donaldson, M. G., Ahamed, Y., Graf, P., Cook, W. L., Close, J., ... \& Khan, K. M. (2008). Otago home-based strength and balance retraining improves executive functioning in older fallers: a randomised controlled trial. Journal of the American Geriatrics Society, 56(10), 1821-1830.

Lord, S. R., Ward, J. A., Williams, P., \& Strudwick, M. (1995). The effect of a 12-month exercise trial on balance, strength, and falls in older women: A randomized controlled trial. Journal of the American Geriatrics Society, 43(11), 11981206.

Madureira, M. M., Takayama, L., Gallinaro, A. L., Caparbo, V. F., Costa, R. A., \& Pereira, R. M. (2007). Balance training program is highly effective in improving functional status and reducing the risk of falls in elderly women with osteoporosis: a randomized controlled trial. Osteoporosis International, 18(4), 419-425.

Matsas, E., \& Vosniakos, G. C. (2017). Design of a virtual reality training system for human-robot collaboration in manufacturing tasks. International Journal on Interactive Design and Manufacturing (IJIDeM), 11(2), 139-153.

McCallum, S. (2012). Gamification and serious games for personalised health. Stud Health Technol Inform, 177(2012), 8596.

Michael, D. R., \& Chen, S. L. (2005). Serious games: Games that educate, train, and inform. Muska \& Lipman/PremierTrade. 
Milani, F., De Marchi, A. C. B., \& Rieder, R. (2017, November). Usability Guidelines to Develop Gesture-Based Serious Games for Health: A Systematic Review. In Virtual and Augmented Reality (SVR), 2017 19th Symposium on (pp. 188194). IEEE.

Mori, B., Carnahan, H., \& Herold, J. (2015). Use of simulation learning experiences in physical therapy entry-to-practice curricula: a systematic review. Physiotherapy Canada, 67(2), 194-202.

Opensimulator (2018) Online at: http://opensimulator.org/wiki/Main Page

Pappa, D., Faltin, N., \& Zimmermann, V. (2009). Applying Business Process Oriented Learning in industry: The PROLIX solution approach based on a case study. International Journal of Advanced Corporate Learning (iJAC), 2(1), 16-24.

Pappa, D. \& Papadopoulos, H. (2018) Designing a prototype training environment for physiotherapists building on advanced gaming technologies. (To appear in) Proceedings of the 17th European Conference on e-Learning (ECEL18), 1-2 November 2018, Athens, Greece

Peffers, K., Tuunanen, T., Rothenberger, M. A., \& Chatterjee, S. (2007). A design science research methodology for information systems research. Journal of Management Information Systems 24(3), 45-78.

Phillips, A. C., Mackintosh, S. F., Bell, A., \& Johnston, K. N. (2017). Developing physiotherapy student safety skills in readiness for clinical placement using standardised patients compared with peer-role play: a pilot non-randomised controlled trial. BMC medical education, 17(1), 133.

Piromchai, P. (2014). Virtual Reality Surgical Training in Ear, Nose and Throat Surgery.

ProFouND (2016a). Deliverable D8.6: Report on Implementation Actions. ProFouND: Prevention of Falls Network for Dissemination. EC ICT PSP Grant Agreement 325087. EU Competitiveness and innovation framework programme (CIP)(2007-2013). Available at: http://profound.eu.com/wp-content/uploads/2016/04/ProFouND-D8.6-Report-onImplementation-Actions-Final.pdf

ProFouND (2016b). Deliverable D1.10: Final Report. ProFouND: Prevention of Falls Network for Dissemination. EC ICT PSP Grant Agreement 325087. EU Competitiveness and innovation framework programme (CIP)(2007-2013). Available at: http://profound.eu.com/wp-content/uploads/2016/04/ProFouND-325087-D1.10-Final-Report.pdf

Protopsaltis, A., Pannese, L., Hetzner, S., Pappa, D., \& de Freitas, S. (2010). Creative learning with serious games. International Journal of Emerging Technologies in Learning (iJET), 5(SI3), 4-6.

Psotka, J. (1995). Immersive training systems: Virtual reality and education and training. Instructional Science, 23(5-6), 405431.

Puentedura, R. (2006). Transformation, technology, and education. [Blog post]. Retrieved from http://hippasus.com/resources/tte/.

Reiners, T., Wood, L., Gregory, S., \& Teras, H. (2015). Gamification design elements in business education simulations. In Encyclopedia of Information Science and Technology (pp. 3048-3061). IGI Global.

Ricciardi, F., \& Paolis, L. T. D. (2014). A comprehensive review of serious games in health professions. International Journal of Computer Games Technology, 2014, 9.

Roberts, F., \& Cooper, K. (2017). The effect of high fidelity simulated learning methods on physiotherapy pre-registration education: a systematic review protocol. JBI database of systematic reviews and implementation reports, 15(11), 2613-2618.

Rubenstein, L. Z., Josephson, K. R., Trueblood, P. R., Loy, S., Harker, J. O., Pietruszka, F. M., \& Robbins, A. S. (2000). Effects of a group exercise program on strength, mobility, and falls among fall-prone elderly men. The Journals of Gerontology Series A: Biological Sciences and Medical Sciences, 55(6), M317-M321.

Santos, M. E. C., Chen, A., Taketomi, T., Yamamoto, G., Miyazaki, J., \& Kato, H. (2014). Augmented reality learning experiences: Survey of prototype design and evaluation. IEEE Transactions on learning technologies, 7(1), 38-56.

Sawyer, B. \& Smith, P. (2008). Serious games taxonomy https://thedigitalentertainmentalliance.files.wordpress.com/2011/08/serious-games-taxonomy.pdf

Schönauer, C., Pintaric, T., \& Kaufmann, H. (2011). Full body interaction for serious games in motor rehabilitation. AH.

Slater M, Spanlang B, Sanchez-Vives MV, Blanke O (2010) First Person Experience of Body Transfer in Virtual Reality. PLoS ONE 5(5): e10564.

Smith, S. N., \& Crocker, A. F. (2017). Experiential learning in physical therapy education. Advances in medical education and practice,

Squire, K. (2011). Video Games and Learning: Teaching and Participatory Culture in the Digital Age. Technology, Education-Connections (the TEC Series). Teachers College Press. 1234 Amsterdam Avenue, New York, NY 10027.

Stiller, K., Lynch, E., Phillips, A. C., \& Lambert, P. (2004). Clinical education of physiotherapy students in Australia: perceptions of current models. Australian Journal of Physiotherapy, 50(4), 243-247.

Susi, T., Johannesson, M., \& Backlund, P. (2007). Serious games: An overview.

Ushaw, G., Eyre, J., \& Morgan, G. (2017). A paradigm for the development of serious games for health as benefit delivery systems. In Serious Games and Applications for Health (SeGAH), 2017 IEEE 5th International Conference on (pp. 1-8). IEEE.

Van Krevelen, D. W. F., \& Poelman, R. (2010). A survey of augmented reality technologies, applications and limitations. International journal of virtual reality, $9(2), 1$.

Wattanasoontorn, V., Boada, I., García, R.J., \& Sbert, M. (2013). Serious games for health. Entertainment Computing, 4 , 231-247.

Witmer, B. G., \& Singer, M. J. (1998). Measuring presence in virtual environments: A presence questionnaire. Presence, 7(3), 225-240. 